\title{
The Security Aspect of Information Society as a Global Biocultural System
}

\author{
Laszlo Z. Karvalics \\ Information Society and Trend Research Institute, Technical University Budapest
}

\begin{abstract}
What about the security of Information Society itself? We examine what are the most prevalent statements related to this system level. Subsequent to analyzing these, we will try to find out what constitutes the 'knowledge sociological/theory of knowledge' domain in which current theories are formulated. After that, we will attempt to comprehensively justify that the discourses dealing with the security issues of the information society could exclusively be built on a foundation of system theory/system dynamics. On the ground of consequences stemming from the application of system theory, we will finally propose to initiate new discourses.
\end{abstract}

Key words: Information Society, Security, System Theory, Risk Society, Evolution

\section{INTRODUCTION}

In the wake of the Internet boom in 1995, an interesting document emerged in Australia. The organization responsible for scientific and technological evolution presented the detailed description of four, increasingly miserable and decreasingly secure scenarios of the digital future [1]. The last one called 'Shipwrecked' is practically a disaster-scenario - let us introduce it now briefly on account of its implications.

"E-cash spreads in parallel with online commerce and becomes a common way of basic payment. The first signs of the trouble emerge in 2003 when a $\$ 50 \mathrm{~m}$ international E-cash fraud is revealed. The increase in E-cash use dramatically drops. (Independently of this, cyberterrorist operations also take place - a worm causes the intelligent agent of million

The original version of this chapter was revised: The copyright line was incorrect. This has been corrected. The Erratum to this chapter is available at DOI: 10.1007/978-0-387-35609-9_29 
PCs to download the complete holdings of the Library of Congress temporarily paralyzing the entire network traffic). Shattered trust in network reliability starts to press back use to communication and entertainment services. The fatal blow comes in 2004 when a tremendous gas-detonation destroying three ATM switching facilities makes the Sydney Exchange ineffective for three days and cuts half million people from using network services. A high-profile new development program commences, but by that time electronic currency diminishes to a minimal scale. It takes a couple of years until the network and the network business recover from the disaster and in parallel with the returning trust the new generation of technology emerges."

Analyzing the disaster-scenario, it becomes conspicuous that the experts envisioning one of the "potential futures" leveraged three different security levels into the scenario: the physical and logical security of the system (destruction of the switching exchange, cracker attack on the network), the security of transactions (E-cash fraud) and the security of the framework institutions (players in electronic currency, stock exchange). They did not fail to bear in mind either that the simultaneous emergence of these three security hazards would bring about a several-year crisis together with the interconnection of local and global elements. But not more than that, however. According to the most pessimistic scenario, the coinciding outlined occurrences would delay the progress of the e-world, nevertheless, after a period of regeneration the processes would still advance imperturbably. So, while, let us assume, the jeopardous environment raises serious security issues for financial services about their "survival", the potential actual decline of these businesses would merely mean an almost imperceptible "wound" in the long run on the more comprehensive level of the e-world.

Our study aims to scrutinize the issues of this "comprehensive level". Whenever a survey dealing with the security problems of any system, amplifying its own significance, can receive the label "... in the information society", we are interested in the security of the information society itself. It would also be interesting and authentic to examine the risks in the phenomenon called pseudonym network identity-tourism [19] by Nakamura, or the auto-reply mail [14], however, security considerations related to the very issue of the development into information society lead to somewhere completely different.

We, therefore, will examine what are the most prevalent statements related to the comprehensive system level (1). Subsequent to analyzing these, we will try to find out what constitutes the 'knowledge sociological/theory of knowledge' domain in which current theories are formulated (2). After that, we will attempt to comprehensively justify that 
the discourses dealing with the security issues of the information society could exclusively be built on a foundation of system theory/system dynamics (3). On the ground of consequences stemming from the application of system theory, we will finally propose to initiate new discourses (4).

\section{THE MOST WIDELY HELD VIEWS CONCERNING THE SECURITY OF THE INFORMATION SOCIETY}

According to our opinion, we can distinguish between four characteristic, partly interrelated views, which will be briefly outlined without any comments using fictitious names to allow us in the third section to refer to them in their analysis and criticism.

\subsection{The complexity paradox}

Holders of the paradox-view claim that the security of complex systems can only be improved suggesting that the development and integration of effective supervising systems further increase complexity. In this way, it is the very intention to enhance security that implies an increasingly uncontrollable integrated system. Accordingly, an increasingly powerful but decreasingly stable system is being built with information society, in which the smallest error or disorder can threat the functioning of the entire system. While the more and more complex and sophisticated solutions seem more and more perfect with their tremendous performance and extraordinary security apparatus, they are actually becoming more insecure.

Increasing instability "in real life" is commonly illustrated by the overinformatized (international) financial system, which, by now, is characterized by the multiplication of the quantity of electronic cash flow and the related insecurity through proliferating meta-transactions.

Ganley [13] demonstrates the default-in-payment spiral launched as a consequence of a single family's falling silver market bonds, which endangered the entire financial system of the United States, back in 1980. The periodically emerging financial-economic crises (Mexico, Southeast Asia, and most recently Argentina) have ever since shattered the security of the financial system more extensively. And no matter how different players are being assured by mechanisms capable of handling these "shakeouts" 
without trouble, the security imperilment seems to be soaring upward while safety still seems to be ensured only on lower levels.

\subsection{Plato revisited}

In the dialogue of Phaedrus, Plato compares writing to a sort of "drug" that apparently helps to improve memory, yet, it actually destroys its very substructure.

Adherents of manuscript copying viewed printing as a process that sacrifices quality for quantity, thus in the long run endangering the foundation of the culture to be preserved. Today, information saved, stored and retrieved in increasingly automated systems evoke the nightmare that unprotected by our (information) technology "clothing" (deprived of tools), we would practically be "naked" unable to survive without the ability to rebuild forgotten skills required in critical situations. And though the development of the given technologies is attributed to endogenous reasons (increased demand to handle information, thus to automatize), the peril intensifies with the change of external, exogenous factors. (Similarly to evolutionary movements of living systems where perfect "organic" adjustment causes non-viability only in the case of an environmental change - in ecological bays the history of the given species cheerfully goes on). Thus, the more precise definition of the danger says 'during the development of the information society we ignore those built-in assurances that by means of the preservation of information management skills developed and common in an earlier technological and social-historical period would provide a chance for taking the adequate action in the case of an environmental change potentially hamstringing the use of the current instrument environment'.

\subsection{The pushbutton effect}

September 11 amplified the communication of vulnerability to the irrationality of "self-destruction". A well-known Hungarian publicist, Ivan Bacher, envisions the atom attack after the terrorist attack, and goes on saying "Atom will be followed by the Internet. By that all people are bound to all the others. The job could be perfectly and totally completed by that." (In the name of Bin Laden some 'expressis verbis' threats were actually expressed saying they intend to destroy the Internet and, through it, the digital world.) 
The logic of panic is clear-cut. Since there are systems of mass destruction that can be guided through direct command control, and because of the fact that these systems are operated by humans, they are ab ovo unpredictable due to the "dark side" of human nature as anyone, anytime can act contrary or crosswise to the logic of system operation, or with unhinged mind. A single push of a button - satellites, computers, controlled institutions, utility networks, and air transport behind - can right away cause catastrophe.

\section{4 'Mantis religiosa' scenario}

The scenario-pair of the slowly and, due to the discounting of the danger, imperceptibly evolving ecological disaster views the possibility as an evolutionary disaster that the compulsion to improve (information and mechanical) systems tends towards a post-human world condition (as 'mantis', this strange locust gobbles up her couple).

Even the new variants of PDAs (personal digital assistant), human organizations augmented by different implants, and the human-machine symbiosis accompanying the current high-end systems of automation and robotics cannot keep step with the enhancement of machine (extrasomatic) intelligence, and as a consequence, a shift takes place at the top of the evolutionary pyramid: humans are being undervalued or eliminated under the shadow of the silico sapiens triumphantly pushing forward.

\section{ON THE KNOWLEDGE SOCIOLOGICAL BACKGROUND TO WIDELY HELD APPROACHES}

What seems immediately apparent when looking at the previously introduced four discourses is the complete lack of their scientific establishment/argument. Even the apparently most scientific complexitytrap is not a scientific one, mainly because (as we will soon pinpoint it) it deals inadequately with categories of system theory; while the other three cases obviously suggest that the issue of system security is a metascientific problem, and that the presented discourses are of ideological nature.

Owing to co-authors Mary Douglas and Aaron Wildawsky, professional literature can analyze ideological starting points for about 20 years [10]. Their work and the evoked debates enable us to distinguish between the most important components and "axes" of the mostly synthetically emerging ideological approaches. 


\subsection{Centrum-periphery axis}

Douglas and Wildawsky circumstantially showcase the characteristics of the center that it is inclined to undervalue long-term hazards. This comes in the nick of time for the much more detail-sensitive "margin" to divert the discourse toward the criticism of the center by articulating the imperilment. The very imperilment, as it becomes a political weapon, is slowly deteriorating to a pretext instead of profound professional disputes. The activist impulse of the periphery communicating "non-continuability" and discontinuity encounters the optimism of the center claiming it is possible to overcome the difficulties. As a consequence, instead of a profound and comprehensive analysis of the environment and the conditions (specific institutional-, economic structural- and interest-features), the security issues concerning the future of the information society tend to descend toward moral categories.

\subsection{Community axis}

On the level of smaller communities, a commonly approved point and intention of the identification of danger is to defend the public good, while incrimination emerges as a derivative of the norm that intends to encourage the other members of the community to contribute to the public good. The community tries to educate and remind its members of their obligation by means of that.

With the unceasing expansion of community size the recognition of dangers and the identification of the delinquents have become more difficult. And while en route to the global society the search, exploration, description and interpretation of the risks have increasingly become one of the core elements of our behavior, no authentic forms of institutions for "public good" and "blaming" adjusted to the new communal size have yet been developed. Stemming from this, everything gets into reference systems constituted for old community sizes, and interpretation proceeds in retrograde ideological structures. (By way of humdrum conspiracy theories instead of functionally grasping the international financial system, and by diabolic capitalists in place of the derivation of the inherent laws of capital flow). 


\subsection{Value axis}

In the 1960s, measles was a widespread disease in the Middle- and Far East. With the help of the Western world several measures were taken to fight off the disease, nevertheless, the ascertainment of the decrease in infant mortality triggered distinctive reactions. Some experts claimed it was an explicit danger that the decrease in infant mortality eliminated a natural "controlling" mechanism, which would result in an unbearable increase in population. However, cultural anthropologists would certainly describe it using a nicer phrase: the problem is actually the slower change in cultural handling methods (patterns) developed in a long time for a given volume of infant mortality as compared to the fast results of the medical campaign.

But how is it possible to measure and define what number of population is "endurable"? And: whatever may our response be, would not growth itself be manageable by new cultural codes, technological and social innovations? What if the ability to grow is the standard of value from the aspect of system function? What sort of specific challenge should the system be prepared for: a challenge to be solved by growth or a one to be resolved by producing balance?

The above examples clearly illustrate that even the seemingly clear-cut value-based approaches lack the scientific principles. The new learning environment of the information society, the extension of the "cognition radius", and the increasing convenience of gathering and processing information are substituted by completely swampy value-imperatives instead of using axiomatic principles. This usually stems from the lack of context - a typical methodological mistake. The fiercest opponents to the penetration of digital culture into schools eagerly cite data and opinion reinforcing the physical "stunting" of children related to the change in their way of life, along the following line of logic: "magnetic attraction" of the computer - too much sitting in front of the screen - spinal complaints, locomotor disorders, and visual impairment - physical deterioration on a generational scale - and other risks! What are we to do with the widely quoted statement of the American Surgeon General saying "young people today are the most sedentary generation in American history"?

How can sedentariness become an ultima ratio in itself? Might there be a continuum where the lack of sitting is the most desirable thing, while the more one sits the "more harmful" it is? Or can we calculate a "non-sedentary quotient", an optimal ratio between sitting and other forms of motions? How is it possible at all to take just sitting out of the system of exercises constituting our time available without paying attention to other features of motion patterns the increase in sitting entails? Where sitting takes up much time from? Is short-term motion more intensive? How much calorie children 
engaging in sports more intensively but for shorter time burn? It is by chance understood from several surveys that the net-generation goes in nature and for sports more frequently than its control groups. It is also understood that it still requires time for excellent ergonomic solutions to become pervasive. There is no doubt that the transformations in the way of life do and may have harmful implications to health. Nevertheless, it is sure that the evaluation of experience related to the physique-change can only be carried out by using methodologies that are able to comprehensively deal with all the aspects of the problem environment.

Even in the case of such an apparently "insignificant" matter as "sitting", system approach is the frame of the answer. Therefore, it is not surprising at all that the "inclusive set" of the "information society" itself universally comprising all trivial and local questions and minor details shall also be surveyed as a supersystem essentially.

\section{INFORMATION SOCIETY AS A GLOBAL BIOCULTURAL SYSTEM}

The new society referred to as information society since the emergence of the phrase in 1961 replacing the industrial era cannot be measured exclusively by the information principle, because its information feature is exposed simultaneously with three further components. That is why Vilmos Csányi could refer to nowadays' society-condition as a "global biocultural system" in his evolution theory [7] [8].

The surveyed system is really global, because "ideas" interpretable exclusively on a global scale are not only being formulated, but are being replicated more and more precisely. Behind them a global infocommunication infrastructure has been established willingly, which creates interconnectivity as the medium of theoretically boundless information exchange. The latest (social) organizational elements almost exclusively characterize, and emerge at, the global system level spectacularly demonstrating the linear interrelation first pointed out by Carneiro between the number of people belonging to the given culture and the quantity of social organizational features that mark a culture [5].

In the same pace as more and more mechanisms of its control loses its spontaneous feature and becomes bound to human activity will biosphere turn to an integral part of society from the "environment" of society - more precisely a component-system equally comprising society and the living nature. Besides humans, objects and living creatures, ideas, as the "puzzlepieces" of culture performing individual evolutionary movement, are 
increasingly being assimilated into this system. This sort of multiple stratification of traditional information security issues can be viewed as a characteristic feature. Virus protection, for example, is as much a matter of strategy and attitude as the complex of accumulated information and the related software is, as Strachan pointed out [16]. Information society can therefore be approached as it really is based exclusively on its system-feature and the current system-dynamics adjusted to the period of life.

The most significant characteristics of this state involve an ongoing system-level leap. Thus, the global biocultural system is just being developed, which also implies that on the global level earlier features of balance and security will no more, while new ones not yet work. On the local level just the opposite is experienced: no matter if the "forerunners" of new solutions promising to address the challenges of interconnectivity emerge, so long as the reproduction of goods and communities can be provided by traditional means, they actually will be in use.

Thus, the new system level suggests a new quality just by means that the different crises of economic-cultural units transformed into system components (thus subsystems) through integration are solved just by the method of organization and division of labor developed for the more comprehensive level and by the new patterns of energy and information transfer. Not by means of growth and reproduction, but by way of a new standard of integration. The crisis-resolution model can the best be showcased by the control-stage of the system cycle.

James Beniger's seminal work in search for the economic and technological roots of the information society got back to the control-crisis increasingly deepening from the beginning of the $19^{\text {th }}$ century, for which the revolution of bureaucracy (and information technology enabling the development of up-to-date bureaucratic mechanisms) was the solution [3]. The signs of perturbation of the resulting balance have been multiplying from the end of the $30 \mathrm{~s}$ of the $20^{\text {th }}$ century; since that time the world has been running toward the next control-crisis in an accelerated speed. Though Beniger does not continue the logic, there is every indication that the new control-revolution resolving the current control-crisis will set in by means of the development of the global institutions of production, consumption, management and control and by way of the development and implementation of global info-communication substructures facilitating the functioning of these institutions.

That is why the practical program of network-based global information infrastructure (GII) replaces the ideology creating the global community of the "global village" through an old, hierarchic way of point-multipoint information diffusion. The metaphors of those visioning the Internet and intranets like a "digital nervous system", or envisioning the millions of 
sensors placed into the atmosphere, the oceans and astronomical observation areas resembling a sort of "digital skin", or essentially visualizing the highcapacity processing units managing increasing input as if it was a World Brain have in common that they attach new component systems to the control-function capable of balancing the global community. Topologically, the cybermap-contours of cables, telephone lines and satellite broadcasts wiring the Earth entirely and seamlessly, and from a business point of view the specifically reducing charges on distance calls as compared to local calls indicate the method "information nervous paths" of the new system level are being developed - and the way the new control-revolution is unfolding.

Beck's well-known concept of risk society also remarks upon the transitional stage between the two system stages with minute detail [2]. According to him, security challenges (from unprecedented new ways of environmental pollution to the development of the global economy) indicate the profound institutional crisis of the industrial society. The actual depth of the crisis, however, cannot be measured by concepts created in the industrial era, and neither can solutions common in the industrial age be expected to handle it. Beck's solution of "reflexive modernity", or Hupet's similar "systematic reflection" program [14] is nothing else than a synonym for the control tailored to the new system level, the global information society.

Steeled with system approach, it soon becomes clear that the views widely held in connection with the security of information society (presented in the first section) are partly mistaken, partly false, and partly unfounded, but are more likely to represent an inadequate abstraction level.

The complexity-paradox, for example, immediately becomes logically indefensible, because the instability spiral stretches only to the system boundary as Norbert Wiener also pinpointed [18]. The system, which is now considered increasingly instable in itself, will reach new forms of stability as part of a more comprehensive system, while on lower system levels solutions prior to the complexity-growth still work happily. The pushbutton-effect must also be reconsidered, just because the controlling mechanisms of the global system level have not yet been developed; there is no such global component system, the catastrophe of which would endanger the entire global system.

If, rejecting the optical distortion of the value-axis, we want to pinpoint the most important aspect, the goal of the system and the standard of value of the functioning of the whole system [6], based on the intention of Churchman, a classic figure in system theory, the anachronistic feature of the "Plato revisited" standpoint will also be revealed. The pressure of evolution and the dynamics of the system constantly drive society toward growth, cognition and integration. Its survival and success depends on its ability to prepare for the future. State-of-the-art information technology 
solutions serve to manage the abundant information load to be processed. Thus, the development of new generations of IT-solutions serving the higher system level is quintessential, because in absence of them the process would got stuck restricted to a lower community scale level. However, all this occurs not as a switch or shift, but via a simultaneous superposition adjusted to the size and function of different system components. The new information technology solution of the higher system level gets on well with the locally used technology of the lower system level.

In the World War II, for example, carrier pigeons still played an important role. Military dovecotes were involved in the battles - just to allow for deployable solutions in case of failures in advanced electronic communication. At the beginning of the 1980s, carrier pigeons carrying blood samples between hospitals or scenarios between local radio studios were still used; however, their role has by now ceased for good. Pigeon-post, the fastest and most advanced way of distance communication for thousands of years, now seems to be left behind functioning communication systems once and for all. Still, does it really mean that the experience accumulated in carrier-pigeon breeding will disappear from society? Not at all. Due to carrier-pigeon breeding (as a sport) more people breed and teach pigeons today than ever in the age of empires and nation(-states) safeguarding their interests with robust monopolies restricting the massive use of pigeon-post. The vast number of books and publications as the vehicles of knowledge on pigeons, and the related culture preserved by the existing breeder communities provide the guarantee for the preservation of the accumulated knowledge. Horribile dictu, the so-called "abrupt launch" (minimizing the risk ahead for the pigeon-post in the shape of the attacking bowmen) developed as a common emergency solution during medieval fortress assaults could still be resuscitated with the help of written records and experienced pigeon breeders even after half a thousand year of unconscious condition.

In order for the knowledge on a quondam information technology solution to be eliminated or become non-reconstructible, it is essential

- to reproduce itself in a narrowing circle continuously losing its functionality,

- that the solutions developed for the latest community system levels "settle down" on the lower level and due to their effectiveness displace the body of knowledge incorporated into xenoliths anyway

- that no demand be made to have the required basic information documented (or these documents be annihilated) 
- not to have such a "secondary" opportunity for utilization that keeps the related knowledge alive in the form of living practice but in a modified environment.

We shall note that nature peoples, staying at earlier phases of different intellectual games and skills, sports and hobby activities, or the use of information technologies, maintain such a broad scale of creative diversity that it is ought to reassure all followers of Plato in the related issue.

The representatives of the 'Mantis religiosa' conception terrified of an overwhelming information development and its post-human impacts probably attended few classes on system theory. Machine intelligence emerges not as a comprehensive component system, but as different functional systems' human-machine subsystems reaching different levels of symbiosis. It is not the "machine feature" what is important, but the resolving power embedded in function. Google's advanced search engine or intelligent agents with increasing semantic capacity revolutionize information management as a collective performance in the field of force of both the developer and the user community. Moreover, computerized mechanical devices searching for cracks in pipe systems, nano-machines incorporated into human organisms, or the Mars-lander transmitting several images avoiding stones have already emerged from the virtual world of bits and play a role in the shaping of real life. The so-called "soft bio-robots" may essentially be the co-evolutionary products of living organisms and computational tools. No matter which variant-form we look at, replication, enhancement and operation will still remain externally controlled (not having a substantial own evolutionary drive) within reasonable time. On the level of the global biocultural system intelligent machines are our integrated and loyal allies. The phantasmagoria of artificial intelligence turning against its "creator" might happen to become a current issue at best in the light of a subsequent system-level leap.

But until that time it is time we started to deal with the actual questions of the security of the information society. Finally, we will pinpoint three discourses of distinct importance involving interrelations we consider important to be debated and profoundly studied as opposed to the views previously criticized. 


\section{RECOMMENDATIONS FOR THE PROMINENT DISCOURSES OF THE SECURITY OF INFORMATION SOCIETY}

\subsection{Cosmic expansion as a system dynamical force}

Having outlined its general evolutionary theory, Csányi [7] claims it is necessary to consider that if the evolutionary logic continues, the global biocultural system itself will also become a replicative unit. Accordingly, "planetary biocultural systems" are to be developed on other planets as well, which influence one another's probability of origination. As long as this occurred, the necessary diversity would be provided to influence the parameters of a new (galactic) system level.

All this emerges as a security problem if the development to a replicative unit will not take place. In this case the process halts, and social history (moreover, the history of living systems, the evolution itself) will remain, to quote the words of Csányi, just an interesting intermediate phenomenon of the physics of low temperatures. This evolutionary "deterioration", in addition, is "internally controlled", since the destruction-scenario needs no external (cosmic) catastrophe. It is far more interesting, however, that the potential success of becoming to a replicative unit must imply the tapping or discharging of such scales of energy sources that would allow us to successfully encounter even some of the cosmic disasters. It is apparent that the "step outward" the next system level has already been made. Humanity has already extended the sphere of its "personal presence" to the Moon, the sphere of "teleoperation" to the Mars, and the sphere of information accumulation well beyond the Solar system. (The phrase "teleoperation" is attributed to Antal Bejczy, one of the "fathers" of the Mars-lander, used to refer to the cross-section of info-communication and robotics).

It is of more than symbolic value that the ideas of space research, information technology and information society have been improving parallel since 1961. The first space flight (Gagarin), the first telephone connection between computers (IBM engineers in Germany) and the emergence of the concept of information society (Tadao Umesao and Kisho Kurokawa) all occurred in 1961. Since that time it has become clearer that information society, due to its cognitive dynamics, is "cosmically oriented". And what is more: despite news headlines about property (parcels available on the Moon), production ("space mining" of sparse raw materials) and space tourism, the "logic" of the universe is post-industrial - and in a sense 
post-historic (it leverages cooperation, requires consensual decisions, and denies information monopolies and expropriation).

Stephen Hawking, the famous astrophysicist, one of the most renowned scientists of the world, announced the accelerated program to "conquer" space and planets fit for habitation in his announcement at the end of 2001 arousing tremendous aversion. Even some of the masterminds regarded it as a delirious fiction, albeit Hawking has only drawn the proper consequences: if available resources can be redeployed to the field by means of a planned policy, the biggest challenge of the near future is the success of the spaceexpansion - in addition the most important (as we have seen: double!) pledge of the security of mankind entering the information society.

\subsection{The preservation of creative diversity}

The global system is inevitably producing more and more common reports, which we can doubtlessly consider as a sort of "homogenization". The preservation of the viability of small cultures is usually dealt with as its counteraction, almost exclusively as part of the spatial asymmetry of cultural freedom, the possession of knowledge and technology, and the issue of minority rights. However, on the other hand, this is equally a matter of system security for the greatest misfortune of bel esprits and those highlighting the primacy of local, (national), traditional culture just over globalization.

The production of new knowledge in the "crushing-mill" of innovation requires more sizable cultural machines. The information society of cognition demands a coordinated research of the most people possible beside a huge scale of capital concentration. Processes of knowledge production increasingly resemble the way industry is. Nevertheless, novel ideas and unexpected innovations emerge just in domains involving no algorithms. What Koestler calls creative action, a common principle beneath creativity [15], is based on a new way of interconnection between remote fields of knowledge. That is why the diversity of languages, schemes of reflection, in situ experiences, and mastery in different worlds of knowledge energizes the entire biocultural system. Knowledge societies are therefore being built as societies of "diverse knowledge", which can be unfolded via the simultaneous movement of the global level of community and meaning and the local cultures. The phrase "multicultural environment" combines these two dimensions, but the emphasis is usually put on one of them. A report titled 'Our Creative Diversity' issued in 1995 by a special UNESCO committee (including Ilya Prigogine and Claude Lévi-Strauss among others), for example, interprets the future of cultures strictly from the aspect of 
locality and universal human qualities [17]. The value of global cultural attributes, however, has not really been acknowledged yet - criticism is usually decisive. Nevertheless, this is a field where anti-globalization efforts do not cause harm to the globalizing system itself as the strengthening of national identity-economies [12] also imply a greater capacity of the entire comprehensive system.

\subsection{The philosophy of danger and risk perception}

Decisions that will one day be conclusive in connection with the security of information society will be based on the risk perception of policymakers of the day and those shaping the common theme.

Closely related to the previous discourse is the profoundly argued thesis of Mary Douglas asserting that risk perception primarily stems not from decisions based on individual, psychical or scientific objectivity, but it is essentially a process bound to cultural binding.

This proposition is in effect enhanced by the concept of "reflexive modernization" (formerly quoted in another aspect) developed by Beck, the theoretician of risk society, as a tool for avoiding global risks [2]. Adjustment will be successful if views, values, norms and forms of behavior become re-examinable in the shape of a sort of "social self-criticism" adjusted to current challenges and proposed alternatives. However, all this appreciates the background information systems and confidential dimension of "decision arrangement" and "decision support", embedded in perception.

Douglas [11] cites the researches of Caplow [4] who recognized that in certain regiments rumors spread like an avalanche. Members of the orderly structured corps, however, always knew what would happen. Those providing reliable information have gained prestige, while those spreading rumors lost their esteem. So, everybody instinctively instructed himself to sensitively censor all fake hearsay developing the practical criteria of the credibility of news.

But how does this "filter" work on the global system level? How can we ensure authentic perception in possession of adequate information? We incorporate the latest news and information into our system of views based on the transformational base we have established up to that time. There are two means to change that. As for argument, by means of the popularization of approaches based on the latest well-founded scientific findings that sweep aside obsolete dilemmas and ideologies replacing expertise with rhetoric. And methodologically, by means of communicating characteristic cultural-, value-, and preliminary knowledge-attributes and the stimulation of the demand for self-reflection. 


\section{REFERENCES:}

[1] ASTEC, 1995: FutureNeeds 2010. Alternative Futures for Full Service Networks in Australia. Australian Science and Technology Council

[2] Beck, Ulrich 1986: Risikogesellschaft. Frankfurt am Main

[3] Beniger, James R. 1986: The Control Revolution. Technological and Economic Origins of the Information Society Harvard Univ. Press

[4] Caplow, Theodore 1947: Rumors in War In: Social Forces, 25.

[5] Carneiro, R.L. 1967: On the relationship between size of the population and complexity of social organization. Southwestern Journal of Anthropology Vol.23. pp.234-243

[6] Churchman, C.West 1968: The Systems Approach Dell Publishing

[7] Csányi, Vilmos 1988: Evolúciós rendszerek (Evolutionary systems) Gondolat,Bp.

[8] Csányi, Vilmos 1989: Evolutionary systems and society: a general theory. Duke University .Press, Durham

[9] Csányi, Vilmos 2000: Az emberi természet (The Human Nature) Magyar Tudomány 4. pp. 397-417.

[10] Douglas, Mary - Wildawsky, Aaron 1982: Risk and Culture. Univ. of California Press, Berkeley

[11] Douglas, Mary 1992: Risk and Blame: Essays in Cultural Theory, London

[12] Everard, Jerry 2000: Virtual States. The Internet and the boundaries of the nation-state. Routledge

[13] Ganley, Oswald H. 1993: Távközlés és információ (Telecommunication and information) Magyar Távközlés 9. 46-49.o.

[14] Hupet, Pierre (ed.) 2001: Risque et systèmes complexes. Les enjeux de la communication Series, Vol.: Non-Proliferation Vol. 2 General Editor: Michel Quentin/ Brunet Sébastien : Bruxelles, Bern, Berlin, Frankfurt/M., New York, Oxford, Wien, 226 p.,

[15] Koestler, Arthur 1964: The Act of Creation Hutchinson \& Co.

[16] Strachan,Glenn 2002: Virus Protection and Security: What Is It and How Do We Respond? TechKnowLogia (http://www.techknowlogia.org/) Vol. 4, Issue 1 January March

[17] UNESCO, 1995: Our Creative Diversity. Report of the World Commission on Culture and Development

[18] Wiener, Norbert 1961: Cybernetics ( $2^{\text {nd }}$ ed.) MIT Press, John Wiley and Sons

[19] Young, Jeffrey R. 2001: Scholars Question the Image of the Internet as a Race-Free Utopia http://chronicle.com/free/2001/09/2001092101t.htm 